\title{
Н.В. Трубавина
}

\section{СЕМАНТИКА ПОДЧИНИТЕЛЬНЫХ СОЮЗОВ В ОСТРОВНЫХ НЕМЕЦКИХ ГОВОРАХ АЛТАЯ ${ }^{1}$}

\begin{abstract}
Целью статьи является описание специфики функционирования подчинительных союзов в устной речи носителей островных верхне- и нижненемецких говоров Алтайского края. Исследование проводится на обширном материале, собранном в ходе экспедииий в немецкие села Алтая в 2003-2013 г2., с привлечением методов сопоставления и контекстного анализа. Автор описывает основные семантические группь подчинительных союзов, выявляет наиболее частотные союзы в каждой группе и разбирает их основные особенности.

Ключевые слова: синтаксис, подчинительные союзы, немецякие диалекты, островные немецкие говоры, Алтайский край.
\end{abstract}

В последнее время становится все более актуальной проблема сохранения родного языка и культуры этнических немцев на территории бывшего Советского Союза. В силу ряда экономических, политических и социальных причин резко возрастает ассимилирующее воздействие языка окружения на островные немецкие говоры. Происходит все более ускоряющаяся смена языка коммуникации в пользу русского языка [1. С. 6]. Несомненно, что в этих условиях островные немецкие говоры Алтайского края нуждаются в неотложном многостороннем описании. Часть современных островных немецких говоров, бытующих на территории бывшего СССР, уже описана, хотя и далеко не все. Огромное число поселений российских немцев не попало в поле зрения исследователей. Чаще описания проводятся в одном аспекте, причем различные уровни языковой системы переселенческих говоров исследованы неравномерно. До последнего времени диалектология занималась в основном фонетикой, морфологией и лексикологией, лишь иногда касаясь области синтаксиса [2]. Среди ученых, так или иначе обращавшихся к проблематике синтаксиса островных немецких говоров, Г.Г. Едиг, Н.А. Пирогов, Н.Н. Степанова, Н.В. Трубавина, И.Г. Гамалей, Н.А. Ермякина. При этом союзы как часть речи предметом специального исследования до сих пор не выступали. Частично средства связи частей сложного предложения в островных немецких говорах затрагиваются в работах Г.Г. Едига (нижненемецкие говоры) и Н.В. Трубавиной (верхненемецкие говоры), посвященных изучению придаточных предложений $[3,4]$, а также в диссертации Н.А. Пирогова, посвященной синтаксису современной нижненемецкой диалектной литературы» [5. C. 31-35]. Состав, семантика, структура как сочинительных, так и подчинительных союзов островных немецких говоров Алтайского края до настоящего времени не получили исчерпывающего описания.

\footnotetext{
${ }^{1}$ Исследование выполнено при финансовой поддержке Российского гуманитарного научного фонда, проект № 12-04-00360 «Текстовый корпус немецких диалектов на Алтае».
} 
Настоящая статья посвящена изучению семантики подчинительных союзов в островных немецких говорах Алтайского края - классов служебных слов, оформляющих синтаксические зависимости одной предикативной единицы от другой [6. С. 484]. Вопрос о семантике союзов как части речи в лингвистической литературе не имеет однозначного решения: одни отрицают наличие у союзов лексического значения и относят их к классу неполнозначных или пустых слов, не имеющих семантической функции [7. С. 335]. Союзы в таком случае рассматриваются либо как «чистая, абсолютная форма» без содержания [8. С. 217], либо как маркер синтаксических отношений «имеющий значение не сам по себе, а как выразитель того или иного сочетания, как словесное обнаружение такого сочетания» (цит. по: [9. С. 578]). Более обоснованной представляется противоположная точка зрения, представители которой, признавая отсутствие у союзов номинативной функции, рассматривают их как носителей особого квалифицирующего или уточняющего значения, благодаря которому они не только выражают подчинительную связь, но и выявляют семантику этой связи [10. С. 293; 11. С. 121-122]. Подобно грамматическим значениям союзы выражают наиболее общие отношения, но не изменением грамматической формы, а собственным лексическим значением [12. С. 373].

Как и в современном литературном немецком языке, союзы в островных немецких говорах Алтайского края являются основным маркером подчинительной и сочинительной связи, одновременно конкретизируя отношения между соединяемыми предложениями или их членами. При этом система союзов в говорах выказывает определенное своеобразие по сравнению как с современным литературным немецким языком, так и с устной разговорной речью, а также с диалектами на территории Германии.

Семантика подчинительных союзов в рассматриваемых говорах менее разнообразна, чем в современном литературном немецком языке, тем не менее они имеют определенный круг лексически выраженных значений, посредством которых уточняют характер связей в предложении. При этом одни союзы узко специализированы, однозначны: weil, hot', solange, их значение зависит от контекста в минимальной степени. Другие же союзы многозначны, полисемичны: wi, wo, tass /daut /dot, значения этих союзов реализуются в контексте, оформляя различные виды смысловых отношений.

По значению среди подчинительных союзов в островных немецких говорах Алтая можно выделить практически те же основные классы, что и в современном немецком языке: союзы, выражающие содержание речи и мысли, временные отношения, причину и следствие, цель, условие, сравнение и уступку, а также выражающие атрибутивные отношения союзы.

Одну из самых многочисленных групп среди подчинительных союзов в островных немецких говорах Алтая представляют временные союзы, отличающиеся разнообразием в отношении формы и оттенков значения. В зависимости от вводимой ситуации все темпоральные союзы в говорах можно разделить на две семантические группы: союзы, выражающие отношения одновременности и союзы, выражающие разновременность. При этом если в литературном немецком языке отношения одновременности и разновременности передаются с помощью подчинительных союзов в сочетании с соот- 
ношением временных форм [13. С. 697; 14. С. 582-584; 15. С. 361], то в рассматриваемых говорах функциональная нагрузка временных союзов изменяется вследствие переноса на них функции выражения дифференцированных временных отношений в результате интенсивных процессов изменения системы временных форм глагола.

Для передачи отношений одновременности употребляются союзы wi, wann / wonn / wånn / wannscht / wonnscht, а также союз solong, который почти всегда выступает в сочетании с другим союзом. Основным и наиболее частотным в этой группе союзов является союз wenn, встречающийся в фонетических вариантах wann / wonn / wånn / wannscht / wonnscht:

Ннем.: Wann de Mäschin bluse däit, dann woite se olla dot fendogh es T'ast büte. = Wenn das Auto hupt, dann wissen sie alle, dass es heute Hochzeit gibt.

Внем.: Wonn te Peder von ti Schul kommt, ruht er sich. = Wenn Peter von der Schule kommt, ruht er sich aus.

С помощью данного союза выражается связь двух ситуаций, во временном отношении протекающих параллельно друг другу. В отличие от современного литературного немецкого языка в верхненемецких говорах данный союз может передавать как многократное, так и однократное действие в настоящем, прошлом и будущем:

Внем.: Jedesmol, wonn ich tes Puuch les, tenk ich on moi Kinnhait. = Jedesmal, wenn ich dieses Buch lese, denke ich an meine Kindheit.

Wonn ich hoom pa moi Elder fahr, nehm ich immer moi Utschebniki mit. = Wenn ich nach Hause zu meinen Eltern fahre, nehme ich immer meine Bücher mit.

Wonn me triwe ware, ti Krenz triwe schunt, in Polscha kummt schon etwa Wech. = Als wir drüben waren, über der Grenze schon, kam in Polen schon etwa Weg.

Лексические конкретизаторы jedesmol, immer, стоящие в главном предложении, дифференцируют семантику союза wann / wonn / wånn / wannscht / wonnscht, подчеркивая повторяемость выражаемого им действия.

Для обозначения однократного действия в прошлом в верхненемецких говорах используется союз wi, в нижненемецких говорах союз os (в современном литературном немецком языке соответствующее значение выражается союзом als):

Внем.: Wi ich te Ouwent hoom komme pin, hen mich schunt moi Froinde kwart. = Als ich abends nach Hause gekommen war, haben mich schon meine Freunde erwartet.

Escht wi ich jinger war, war ich rawnoduschna zu tene Plumen. = Zuerst, als ich jünger war, war ich gleichgültig zu denen Blumen.

Ннем.: Os dei dem Rezapt den Dokta weis, word fuz olles kloa. = Als sie das Rezept dem Doktor zeigte, war alles sofort klar.

Dot wi ne oule Schoul, en os se ne nie büte, dann nome se det. = Das war eine alte Schule, und als sie eine neue gebaut hatten, dann nahmen sie das.

Другим частотным союзом для выражения отношений одновременности является союз solong, указывающий на равную продолжительность одновременно протекающих действий главного и придаточного предложений:

Внем.: Solong wi me jetz noch so sin, mer kenn noch schawe. = Solange wir jetzt noch so sind, können wir noch arbeiten. 
Solong wi te Wech zu is, musem tes umfahre. = Solange der Weg zu ist, muss man den umfahren.

Ннем.: Bi ons wortet bot nü tö, wins, solang os hia dise Mensche wire, wot hia wune doide, doi starije Shiteli, wire äma viil Mensche ap em Bejerafnes. = Bei uns war das bis jetzt zu, weil, solange hier diese Menschen waren, welche hier gewohnt hatten, die alten Einwohner, waren immer viele Menschen bei dem Begräbnis.

Как видно из примеров, данный союз образует комбинации с другими союзами: solong wi, solang os, sou lang ous, solang bot. На территории Алтайского края данный союз зафиксирован как в верхненемецких, так и в нижненемецких островных говорах [16]. Употребление составного подчинительного союза so lang wi отмечено и в островных немецких говорах стран Европы [17. С. 57], а также в диалектах на территории Германии [18. С. 137; 19. C. 137]. Кроме того, комбинация союзов solange wie широко реализуется и в разговорном гипотаксисе немецкого языка [20. С. 124]. Все это ставит под сомнение предположение о том, что союз solange в островных нижненемецких говорах Алтайского края заимствован из литературного немецкого языка [3. C. 18].

Союзы для выражения отношений разновременности в островных немецких говорах Алтая могут иметь значение предшествования или следования одного действия за другим, характеризуя отношения между действиями с разных сторон:

Er hot ti Maschiin kefillt, ehp se kfahre sin. = Er hatte das Auto getankt, ehe sie fuhren.

Se sin kfahre, noch tes wi er ti Maschiin kefillt hot. = Sie fuhren, nachdem er das Auto getankt hatte.

Следование выражается союзами ehp / ehpst / ehpscht / eja / oja / oja os, ve$\mathrm{rem} /$ vorcher / tevor, vor tes wi / ver daut wi / ver dem dot / vor tem tass, von dann os, bis /pis /piste /pischt /bet /bot. Все союзы данной группы употребляются в значении «перед тем как», «прежде чем», «до того, как». В сложных предложениях с союзами следования действие главного предложения происходит раньше действия придаточного, следующего за ним:

Внем.: Er hot schon alles kewusst, tevor ich te Maol ufkemacht hun. = Er hatte schon alles gewusst, bevor er das Maul aufmachte.

Ннем.: Dü motst de Hüüsofgabe moke, eja dü jejst. = Du musst die Hausaufgabe machen, ehe du gehst.

Союз bis /pis /piste /pischt / bet /bot указывает на то, что действие, описанное в главном предложении, продолжается лишь до начала действия придаточного предложения:

Внем.: Pis er recht kekocht hot, hun ich Kartowel keschält, o pissje Riwe, Kelriwe, hun ich tes alles noikeschmise. $=$ Bis es recht gekocht hatte, habe ich Kartoffeln geschält, ein bisschen Rübe, Mohrrübe, habe ich das alles hineingeschmissen.

Ннем.: Blous rene Sarplata, dan bloiv duo nech viil, bot se han en tred' fohre, fu dot Kontore tule en ite en olle Sorte. $=$ Bloß reines Gehalt, dann bleibt da nicht viel, bis sie hin und zurückfährt, für das Büro zahlt und für das Essen und so weiter.

Нередко данный союз выступает в сопровождении отрицательной частицы net = nicht или отрицательного местоимения ko = kein, keine. В современ- 
ном литературном немецком языке отрицание данному типу придаточных предложений не свойственно. Оно появляется под воздействием соответствующей русской конструкции пока не:

Внем.: Ehr kennt paar Taghe pa uns wohne, pis ehr sich $\underline{k o}$ Haos fint. = Ihr könnt paar Tage bei uns wohnen, bis ihr sich ein Haus findet.

Pis ich te Prifung $\underline{\text { net }}$ apkewe hun, konn ich nirgens net hinfahre. $=$ Bis ich die Prüfungen abgegeben habe, kann ich niergendwohin fahren.

Для выражения следования в верхненемецких говорах может быть также использован полифункциональный союз wi, значение которого нередко уточняется лексическими конкретизаторами:

Внем.: Wi ich mit moi Arwait ferdig war, hun ich ten Froint keholwe. = Nachdem ich mit meiner Arbeit fertig war, habe ich dem Freund geholfen.

Kraat wi ich oikeschlouwe pin, hot te Telefon kerabbelt. = Sobald ich eingeschlafen bin, hat das Telefon geklingelt.

Wi te Fisch kekliit hot, is er klaich in Lotke komme. = Sobald der Fisch angebissen hat, ist er gleich ins Boot gekommen.

В приведенных примерах семантическая ограниченность многозначного союза восполняется употреблением наречий kraat и klaich, которые подчеркивают, что действия происходят сразу одно за другим.

Появление в говорах составного союза vor tes wi /ver daut wi /ver dem dot /vor tem tass; von dann os, который встречается преимущественно в речи младшего поколения информантов, объясняется влиянием русского языка: данный союз образован путем точного перевода русского союза «перед тем как»:

Внем.: Ich muss mich escht rasire, vor tes wi mer kehe. = Ich muss mich zuerst rasieren, bevor wir gehen.

Ннем.: Vere dot wach'fore, guht ischt en de Loftje. = Bevor wir wegfahren, geht man erst in den Laden.

Аналогичную схему построения имеет сложный союз nu dem dot / nu dem os /noch tem wu (wi) /nume dann, употребляемый для выражения отношений предшествования:

Внем.: Ich war peis, noch tes wi si traimol kesaat hot «Fahr sachtiger!» $=$ Ich war böse, nachdem sie dreimal gesagt hatte «Fahr sachter!»

Ннем.: Wi sehe din mou seja wenig, nu dem os di send hiijetrocke. = Wir haben sie selten gesehen, nachdem sie übergesiedelt sind.

Данный союз предположительно появляется в говорах в результате калькирования русского подчинительного союза «после того как».

Помимо упомянутого калькированного союза nu dem dot /nu dem os /noch tem wu (wi) /nume dann предшествование в рассматриваемых говорах может выражаться союзами os, wi, а также составным союзами wann... futs, krat... so.

В нижненемецких говорах в этом значении получает широкое распространение союз os:

Ннем.: De Oula wi lang krank, os hei met det Peed on'a Iis jen't'. = Der Alte war lange krank, als (nachdem) er mit dem Pferd unters Eis ging.

Как и в верхненемецких говорах, для уточнения значения союза могут использоваться лексические конкретизаторы: 
Ннем.: Es väja oda fiif W'et' rom, von donn os hei storw. = Sind vier oder fünf Wochen rum, seitdem er starb.

В одном из верхненемецких примеров нам встретилось также употребление союза sobald для выражения отношений предшествования:

Внем.: Sobald te Salz truf, konn me ese. = Sobald das Salz darauf ist, kann man essen.

Однако единичность употребления данного союза и знание респондентом современного литературного немецкого языка позволяют предположить, что выражение предшествования посредством союза sobald pacсматриваемым говорам не свойственно. Скорее всего, это является следствием интерференции литературного немецкого языка, что подтверждает и опрос носителей говора: остальные респонденты не знают союз sobald совсем или не употребляют его в речи.

Для выражения отношений причины островные немецкие говоры располагают гораздо меньшим количеством союзов: wail / weil / wils / winst, ras. Как и в современном литературном немецком языке, основным союзом, выражающим причинную связь между ситуациями, является союз wail / weil / wils / winst. Действие придаточного предложения, вводимого данным союзом, описывает обстоятельство, служащее основанием (поводом) для действия, описываемого главным по составу предложением:

Внем.: Ich hun alles keheert, wail ich tenewich kestone hun. = Ich habe alles gehört, weil ich daneben gestanden habe.

Wail ich miid war, pin ich oikeschlouwe hinich ti Picher. = Weil ich müde war, bin ich eingeschlafen hinter den Büchern.

Ннем.: Poita t'aft schmoke Blöme, winst dim sine Ma hat Jeburstag. = Peter kauft schöne Blumen, weil seine Mutter Geburtstag hat.

Причинные отношения в сложноподчиненном комплексе могут передаваться и союзами wi и wo /wu, сохранившими значение каузальности, характерное для ранних периодов развития языка. Зависимая предикативная конструкция в таких случаях обычно стоит перед главным предложением:

Внем.: Un wi s n Kriich war, ten Kerl hen se keschose. = Und da es Krieg war, den Kerl haben sie geschossen.

Ннем.: Wo me in Russlond wohnt, tut es ten tak ws'o rawno weh. = Wenn man in Russland wohnt, tut es denn sowieso weh (so was zu hören).

Нам также встретилось употребление русского разговорного союза «раз» для подчинения придаточных предложений причины:

Mer tenge so, ras hot er so viil Schnaps ketrunge. = Wir denken so, weil er so viel Schnaps getrunken hat.

Иногда для передачи причинных отношений респонденты употребляют сложные союзы wege tes, tass /wege tes, wail, появление которых в говорах предположительно связано с влиянием русского языка:

Внем.: Schun wege tes, tass er tes Puch keschriwe hot, is er pukonnt kewore. $=$ Schon deswegen, dass er das Buch geschrieben hat, ist er bekannt geworden.

Ich traa Prill, wege tes, wail ich schwach seh. = Ich trage Brille, weil ich schlecht sehe. 
Построения такого типа сходны с причинными конструкциями в русском языке, что позволяет предположить, что данные составные союзы построены по схеме русского союза «из-за того, что».

Для выражения отношений цели используются союзы tass /dot /daut, tass hot', om dot /em daut, sau daut/so tass /so dass. Действие присоединяемого данными союзами придаточного предложения рассматривается как желаемое, предполагаемое, должное, выражает намерение, цель, надежду:

Внем.: Vuzähl pissje laoder, tass ich tich vustehe. = Sprich bisschen lauter, dass ich dich verstehe!

Ннем.: Wi ha olles vekooft, det doi konn sech liire. = Wir haben alles verkauft, dass er lernen kann.

Как и в современном немецком языке, реализуя целевое значение, полисемичный союз tass / dot / daut выражает обусловленность, при которой действие в придаточном предложении выступает как реальный или потенциальный результат действия главного предложения. В островных немецких говорах Алтая данный союз нередко употребляется в сочетании с заимствованной из русского языка частицей «хоть», преимущественно для выражения желания в настоящем и будущем:

Внем.: Mer hade alles vukawe, tass mer hot' o kloone Pissje Kelt hen. = Wir hatten alles verkauft, damit wir wenigstens ein kleines Bisschen Geld haben.

Союз tass / dot / daut является и самым распространенным средством передачи отношений следствия в говорах:

Внем.: Un hia is o arich scheines Kebet, awer to kuck ich schun konz schwach, tass ich net arich konn lese. $=$ Und hier ist ein sehr schönes Gebet, aber da sehe ich schon ganz schlecht, dass ich nicht gut lesen kann.

Awer mondje Lait kenne tes net lose, tass se tort sterwe kenne. $=$ Aber manche Leute können das nicht aushalten, so dass sie dort sterben können.

Реже отношения следствия выражаются союзом so tass / sou dat = so tass:

Внем.: Siibzehn Johr hun ich kearwait Sanitarkoj w Roddome, so tass ich tes waiß un hun net omool kesehe. $=$ Siebzehn Jahre habe ich als Krankenschwester im Entbindungsheim gearbeitet, so dass ich das weiß und nicht einmal das gesehen habe.

Оба союза указывают на непосредственный результат действия в главном предложении.

Из многочисленных союзов, используемых в современном литературном немецком языке для выражения уступительных отношений, в речи носителей говора встречается лишь союз wenn ... uk /wann ook /wenn ach /wann ... ok /woun uk /wonn aach = wenn auch, называющий ситуацию, вопреки которой осуществляется действие главного предложения:

Внем.: Wonn si ti taitsche Namen aach hen, sin si ko Taitsche. = Wenn sie auch deutsche Namen haben, sind sie keine Deutschen.

Ннем.: De Älste ju, met dine jejt tu ride, wann soi uk nech krait olles vlächt jeripe, uba met din jejt. = Die Ältesten ja, mit denen geht es noch zu reden, wenn sie auch nicht gerade alles vielleicht verstehen, aber mit denen geht es.

С данным союзом в говоре успешно конкурирует заимствованный из русского языка разговорный союз hot' в том же значении: 
Внем.: Ich tenk net, tass es so is, hot' Paol so nastaiwaje. = Ich denke nicht, dass es so ist, obwohl Paul so darauf besteht.

Ннем.: Hot' doi hod viil Obet, uba doi fund fe ons Tiit. = Obwohl er viel Arbeit hatte, hat er für uns doch Zeit gefunden.

Значение сравнения передается в говорах союзами wi; kabudto; os / als / wai / als wann (wonn). В верхненемецких говорах для сравнения как равнозначных, так и неравнозначных действий, качеств и состояний употребляется союз wi. Подчинительный союз als, используемый в современном литературном немецком языке при сравнении неравнозначных действий (состояний, качеств), носителями говоров не употребляется:

Внем.: Ter hot nix uf, is nagich, hot ko Prodje, so wi mer ran'sche kelebt hun. = Der hat nichts an, ist nackt, hat kein Brot, so wie wir früher gelebt haben.

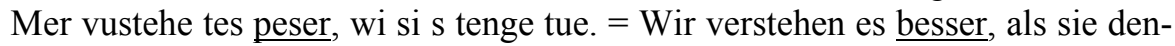
ken.

Носители нижненемецких говоров Алтайского края в сравнительных предложениях чаще всего употребляют союз os /als:

Dot Buuk wi nech so interessont, os wi dachte. = Das Buch war nicht so interessant, als wir dachten.

Нереальное сравнение в рассматриваемых говорах выражается при помощи союза als wonne (wann), при этом сказуемое зависимой предикативной конструкции стоит в конъюнктиве:

Внем.: Mer turfte net uf ti Kass, als wonne mer Faschisty wäre. = Wir durften nicht auf die Straße, als wenn wir Faschisten wären.

Действия, сравниваемые с помощью данного союза, не равнозначны, не эквивалентны, а только кажутся таковыми.

Для выражения отношений условия в островных немецких говорах Алтая используются союз wann /wonn /wånn, а также многозначный союз wi. Кроме того, иногда можно встретить сочетание in Fall wonn в значении «in dem Falle, wenn»:

Внем.: In Fall wonn ich ti Exameny net apkef, fahr ich net hoom. = In dem Falle, wenn ich die Prüfungen nicht ablege, fahre ich nicht nach Hause.

Самый употребительный в данной группе союз wann /wonn /wånn носит условно-предположительный характер: действие реализуется только в случае выполнения какого-либо условия:

Внем.: Wonn noch was passiat, rabl ich tich on. = Wenn noch etwas passiert, ruf ich dich an.

Wonn ti Tochta noch fahrt, wo plaip ich tenn? = Wenn die Tochter noch fährt, wo bleibe ich denn?

Ннем.: Wenn et' wust, det dü hiir wuhnst, wu et' soulang jekume sene. = Wenn ich wüsste, dass du hier wohnst, wäre ich schon lange gekommen.

Употребление заимствованной из русского языка частицы «бы»» придает союзу значение недостоверности, нереальности ситуации:

Внем.: Wonn by wär mejne Regh'er, täide me on raicherer Uroshai zommerome. $=$ Wenn es mehr Regen wäre, hätten wir bessere Ernte gesammelt.

Как и в гипотаксисных построениях с отношениями времени, в зависимых предикативных конструкциях условия союз может предвосхищать окончание 2-го лица единственного и множественного числа глагола: 
Внем.: Wonnste ti Uroge kemacht host, kennstu kehe, wostu hin willst. = Wenn du die Hausaufgaben gemacht hast, kannst du gehen, wohin du willst.

Wonndr keht uf ten Wech, to kehdr in ti Schuul. = Wenn ihr geht diesen Weg, so kommt ihr in die Schule.

Определительные отношения реализуются в островных верхненемецких говорах Алтая преимущественно при помощи союзного слова wo / wu, нередко в сочетании с относительными местоимениями, например:

Внем.: Tes sin Lait, ti wostu Kelt kelije host. = Sind das die Leute, denen du Geld geliehen hast?

Ich kehe ti Lait aus te Wech, wo mich net kefalle. = Ich gehe den Leuten aus dem Weg, die mir nicht gefallen.

Встречаются также примеры с союзами tass и ob, например:

Внем.: Were viillaicht Zait komme, tass mer wohl lewe. = Wird vielleicht Zeit kommen, wenn wir wohl leben.

Ti Frouch, op es wohr is, lost mich net in Ruhe. = Die Frage, ob es wahr ist, lässt mich nicht in Ruhe.

Носители говора избегают употребления относительного местоимения welcher / welches / welche, а также комбинации предлогов с относительными местоимениями ter, ti, заменяя их по возможности союзным словом wo/wu:

Внем.: Un ti zwait Schwester, wo kestorwe is, ti hot siwe Klass keendigt. = Und die zweite Schwester, die gestorben ist, die hatte sieben Klassen beendet.

Mer hade $\mathrm{n}$ krous Stuup, wo alle keschlouwe un kekese hen. = Wir hatten eine große Stube, in der alle geschlafen und gegessen haben.

Es weat pa uns in Klup n Ouwent kemacht, wo sich ti Junge zammeromme. No kehe aach ti äldere Lait hin. = Es wird bei uns im Klub ein Abend veranstaltet, zu dem sich die Jugendlichen versammeln, aber es gehen auch die älteren Leute dorthin.

Использование данного союза было характерно для более ранних периодов развития немецкого языка [21. С. 232-233]. В современном литературном немецком языке данный союз неупотребителен, однако он сохранился сегодня в разговорной и диалектной речи, где нередко употребляется в качестве всеобщего показателя относительного подчинения [22. C. 378; Post. C. 136; 20. C. 118].

Возможно также употребление союзного слова wo/wu с предлогом:

Un tes Johr, iwer wo ich tes Kelt zomme hun keroppt, in tes Johr hun ich mich zwai Kilo Panane kaaft un o Kilo Äbel. = Und das Jahr über, in dem ich das Geld gesammelt habe, in dem Jahr habe ich mir zwei Kilo Bananen gekauft und ein Kilo Äpfel.

В данном случае мы можем наблюдать ослабление синтаксической связи в предложной группе «tes Johr iwer» = «das Jahr über», в результате которого предлог iwer примыкает к союзному слову wo, вводящему придаточное предложение.

В нижненемецких островных говорах в данных значениях союз wo не встречается. В речи носителей он выступает эквивалентом немецкому литературному союзу и наречию wie:

Ннем.: Wo schud mi dot nech es, konn et' noscht moke. = Wie schade mir das auch ist, kann ich nichts machen. 
Et' ha nech jefrougt, wo lang di en Ditschlond wuhne. = Ich habe nicht gefragt, wie lange die in Deutschland wohnen.

Небольшая по численности группа изъяснительных союзов представлена одним из самых частотных союзов - союзом tass / daut / dot, выражающим содержание речи и мысли, и довольно редко встречающимся союзом ob, присоединяющим придаточное предложение с косвенным вопросом:

Внем.: Si wille ach, tass pa tene ach alles schej is. = Sie wollen auch, dass bei denen auch alles schön ist.

Ннем.: Doi Predprinimatel', doi hod din vesprocke, dot doi din wut ärent wo hanschete, wude se ne Put'ovka t'ri. = Der Unternehmer, der hat denen versprochen, dass er sie irgendwohin schickt, dass sie eine Reise kriegen werden.

C точки зрения семантики данная группа союзов не обнаруживает никаких особенностей по сравнению с современным литературным немецким языком: это наименее наполненные значением союзы.

Таким образом, подчинительные союзы в островных немецких говорах Алтайского края отличаются вариативностью форм и распределяются по девяти основным классам в зависимости от семантики и выполняемых функций - временные, причинные, цели и следствия, уступки, сравнения, условные, определительные и изъяснительные:

Состав союзов в островных немецких говорах Алтая в сравнении с современным литературным немецким языком

\begin{tabular}{|c|c|c|}
\hline Выражаемая семантика & Островные немецкие говоры & Лит. нем. язык \\
\hline 1 & 2 & 3 \\
\hline $\begin{array}{l}\text { Отношения времени: } \\
\text { одновременность }\end{array}$ & $\begin{array}{l}\text { wann /wonn /wånn /wannscht / } \\
\text { wonnscht } \\
\text { os } \\
\text { solong/solang, soulang, aber: sau } \\
\text { lang } \\
\text { solong wi / solang os } \\
\text { solang bot } \\
\text { bet wi }\end{array}$ & $\begin{array}{l}\text { wenn } \\
\text { als } \\
\text { solange } \\
\text { während } \\
\text { indem, indes(sen) } \\
\text { sobald } \\
\text { sooft } \\
\text { wie, sowie }\end{array}$ \\
\hline $\begin{array}{l}\text { Отношения времени: пред- } \\
\text { шествование }\end{array}$ & $\begin{array}{l}\text { nu dem dot / nu dem os / noch tem } \\
\text { wu (wi) / nume dann wann } \\
\text { wi } \\
\text { os } \\
\text { wann ... futs } \\
\text { krat ... so }\end{array}$ & $\begin{array}{l}\text { nachdem } \\
\text { als } \\
\text { sobald } \\
\text { seit, seitdem } \\
\text { wie, sowie } \\
\text { sooft } \\
\text { wenn } \\
\text { kaum dass }\end{array}$ \\
\hline $\begin{array}{l}\text { Отношения времени: } \\
\text { следование }\end{array}$ & $\begin{array}{l}\text { ehp/ehpst/ehpscht/eja/oja } \\
\text { oja os } \\
\text { verem/vorcher/tevor } \\
\text { bis/pis/piste/pischt/bet/bot } \\
\text { pis net } \\
\text { vor tes wi / ver daut wi / ver dem dot } \\
\text { / vor tem tass } \\
\text { wi / nort wi } \\
\text { sobald } \\
\text { von dann os }\end{array}$ & $\begin{array}{l}\text { ehe } \\
\text { bis } \\
\text { bevor }\end{array}$ \\
\hline Причина & $\begin{array}{l}\text { wils / wail / weil / winst } \\
\text { ras } \\
\text { wi } \\
\text { wo /wu }\end{array}$ & $\begin{array}{l}\text { weil } \\
\text { da } \\
\text { zumal (da), } \\
\text { um so mehr als } \\
\text { dafür, dass }\end{array}$ \\
\hline
\end{tabular}


Окончание таблицьь

\begin{tabular}{|c|c|c|}
\hline 1 & 2 & 3 \\
\hline Следствие & $\begin{array}{l}\text { tass / daut } \\
\text { soa } \ldots \text { tass }\end{array}$ & $\begin{array}{l}\text { dass, } \\
\text { so-dass, so dass } \\
\text { um - zu, zu } \\
\text { zu-als-dass } \\
\text { wie }\end{array}$ \\
\hline Цель & $\begin{array}{l}\text { tass / daut } \\
\text { tass } \text { hot }^{6} \\
\text { om dot/em daut } \\
\text { sau daut / so tass / so dass }\end{array}$ & $\begin{array}{l}\text { dass } \\
\text { damit } \\
\text { auf dass } \\
\text { um - zu } \\
\end{array}$ \\
\hline Условие & $\begin{array}{l}\text { wi } \\
\text { wann / wonn / wånn }\end{array}$ & $\begin{array}{l}\text { wenn, auch wenn } \\
\text { wofern, sofern } \\
\text { falls } \\
\text { außer wenn, es sei denn... } \\
\text { je...desto/um so } \\
\text { je nachdem, ob, je nachdem, w- }\end{array}$ \\
\hline Сравнение & $\begin{array}{l}\text { wi } \\
\text { os / als / wai / als wann (wonn) } \\
\text { kabudto }\end{array}$ & $\begin{array}{l}\text { wie } \\
\text { als, als ob, als wenn } \\
\text { gleichwie } \\
\text { sowie, so-wie } \\
\text { wie wenn }\end{array}$ \\
\hline Уступка & $\begin{array}{l}\text { wenn ... uk / wann ook / wenn ach / } \\
\text { wann .. ok / woun uk / wonn aach } \\
\text { hot }^{*} \\
\text { obwi } \\
\text { wann dashe }\end{array}$ & $\begin{array}{l}\text { wenn auch } \\
\text { obgleich, obwohl, obschon, } \\
\text { obzwar } \\
\text { wenngleich, wennschon } \\
\text { trotzdem }\end{array}$ \\
\hline Содержание речи/мысли & $\begin{array}{l}\text { tass / daut /dot } \\
\text { ob }\end{array}$ & $\begin{array}{l}\text { dass, außer dass, nu dass } \\
\text { ob } \\
\text { was... } \\
\text { insofern } \\
\text { soviel } \\
\text { soweit } \\
\text { wobei }\end{array}$ \\
\hline Атрибутивные отношения & wo /wu & $\begin{array}{l}\text { Только относительное подчи- } \\
\text { нение }\end{array}$ \\
\hline $\begin{array}{l}\text { Противительные отноше- } \\
\text { ния }\end{array}$ & не зафиксированы & während \\
\hline $\begin{array}{l}\text { Способ совершения дейст- } \\
\text { вия }\end{array}$ & не зафиксированы & $\begin{array}{l}\text { indem } \\
\text { dadurch-dass, so-dass } \\
\text { wobei } \\
\text { ohne zu, ohne dass } \\
\text { statt } \\
\text { außer dass, außer zu }\end{array}$ \\
\hline
\end{tabular}

В целом семантика этих классов соответствует современному литературному немецкому языку, за исключением союзов образа действия и противительных союзов, не представленных в рассматриваемых говорах, а также атрибутивного союза wo/wu, не характерного для современного немецкого языка. Однако наполняемость семантических классов в говорах иная, чем в литературном немецком языке - в синонимическом ряду союзов в диалекте остаются наиболее частотные и древние союзы, семантика которых в некоторой степени «стирается» и требует опоры на контекст: врем. während, indem, sobald, sooft $\rightarrow$ wenn; условн. wenn, auch wenn, wofern, sofern, falls, außer wenn, es sei denn... $\rightarrow$ wie, wenn; уступит. wenn auch, obgleich, obwohl, obschon, obzwar, wenngleich, wennschon $\rightarrow$ wenn auch. Это приводит к уменьшению количества союзов в рассматриваемых говорах, однако беднее состав 
союзов не становится - в каждой из семантических групп присутствуют специфические диалектные союзы, нехарактерные для современного литературного немецкого языка: wo / wu, um dass, verem / vorcher / tevor, von dann os, nu dem dot / nu dem os /noch tem wu (wi)/nume dann, и др. Кроме того, состав союзов в говорах расширяется за счет фонетических вариантов (ehe = ehp/ehpst/ehpscht/eja/oja), за счет способности союзов сочетаться друг с другом (solange = solong, sau lang, solong wi, solang os, solang bot), а также за счет заимствований из контактирующего русского языка: hot', kabudto и др.

Таким образом, при сходстве выражаемой семантики состав союзов островных немецких говоров Алтая существенно отличается от состава союзов современного литературного немецкого языка. Подчинительные союзы в островных немецких говорах Алтайского края не являются закрытым классом слов, что открывает широкое поле для дальнейших исследований.

\section{Литература}

1. Москалюк Л.И. Социолингвистические аспекты речевого поведения российских немцев в условиях билингвизма. Барнаул: Изд-во Барнул. гос. ун-та, 2000. 166 с.

2. Hilkes $P$. Zur Lage der deutschen Minderheiten in der Sowjetgesellschaft. München: Osteuropa-Institut, 1990. $15 \mathrm{~S}$.

3. Едиг Г.Г. Придаточные предложения нижненемецкого говора Алтайского края: автореф. дис. ... канд. филол. наук. Томск, 1962. 39 с.

4. Трубавина Н.В. Особенности развития зависимых предикативных конструкций в островном верхненемецком говоре: автореф. дис. ... канд. филол. наук. Барнаул, 2003. 20 с.

5. Пирогов Н.А. Синтаксис современной нижненемецкой диалектной литературы: автореф. дис. ... канд. филол. наук. М., 1980. 27 с.

6. Языкознание: большой энциклопедический словарь / гл. ред. В.Н. Ярцева; ред. кол. Н.Д. Арутюнова и др. 2-е изд., репринт. М.: Большая рос. энцикл., 1998. 685 с.

7. Теньер Л. Основы структурного синтаксиса / пер. с фр. И.М. Богуславского; авт. предисл. В.Г. Гак. М.: Прогресс, 1988. 654 с.

8. Пешковский А.М. Русский синтаксис в научном освещении; [вступ. ст. Ю.Д. Апресяна; предисл. к 7-му изд. А.Б. Шапиро]. 8-е изд., доп. М.: Языки славянской культуры, 2001. 544 с.

9. Виноградов В.В. Русский язык: (Грамматическое учение о слове) / под ред. Г.А. Золотовой, 4-е изд., М.: Рус. яз., 2001. 720 с.

10. Реформатский A.A. Введение в языковедение: учеб. для студентов филол. специальностей вузов / под ред. В.А. Виноградова. [5-е изд., уточн.]. М.: Аспект Пресс, 2000. 536 с.

11. Гульга Е.В., Натанзон М.Д. Теория современного немецкого языка (грамматика). Ч. 2: Синтаксис. М.: Знание, 1959. 173 с.

12. Москальская О.И. Грамматика немецкого языка: теоретический курс: учеб. пособие для студентов / под ред. И. Шехтера. М.: Изд-во лит. на иностр. яз., 1958. 394 с.

13. Duden. Grammatik der deutschen Gegenwartssprache. Mannheim; Wien; Zürich: Bibliographisches Institut, 1984. $800 \mathrm{~S}$. $629 \mathrm{~S}$.

14. Helbig G, Buscha J. Deutsche Grammatik. Leipzig: VEB Verlag Enzyklopädie, 1977.

15. Schendels E.I. Deutsche Grammatik. Moskau: Verlag Hochschule, 1982. 400 S.

16. Москалюк Л.И., Трубавина Н.В. Лингвистический атлас немецких диалектов на Алтае: в 2 ч. Ч. 2. Барнаул: АлтГПА, 2011. 199 с.

17. Wild K. Syntax eingeleiteten Nebensätze in den "Fuldaer" Deutschen Mundarten Ungarns. Budapest: Akad.K., 1994, 257 S.

18. Weise O. Altenburger Mundart. Leipzig: Breitkopf\&Händel, 1900.164 S.

19. Post R. Pfälzisch. Einführung in eine Sprachlandschaft. Landau/Pfalz: Pfälzische Verlagsanstalt $\mathrm{GmbH}, 1992.399 \mathrm{~S}$.

20. Поликарпов А.М. Сложное предложение в синтаксисе немецкой разговорной речи. Архангельск: Помор. гос. ун-т. им. Ломоносова, 2000. 446 с. 
21. Moskalskaja O.I. Deutsche Sprachgeschichte. Moskau: Verlag Hochschule, 1985. 280 S.

22. Жирмунский В.М. Немецкая диалектология. М.; Л.: Изд-во АН СССР, 1956. 636 с.

\section{SEMANTICS OF SUBORDINATE CONJUNCTIONS IN THE ORAL SPEECH OF UPPER- AND LOW-INSULAR ALTAI GERMAN DIALECTS.}

Tomsk State University Journal of Philology, 2015, 3(35), pp. 93-106. DOI 10.17223/19986645/35/8

Trubavina Nina V., Altai State Pedagogical Academy (Barnaul, Russian Federation). E-mail: tschichni@mail.ru

Keywords: syntax, subordinate conjunctions, German dialects, insular German dialects, Altai.

The aim of this paper is to describe the functioning specificity of subordinate conjunctions in the oral speech of upper- and low-insular Altai German dialects. It is based on the practical material gathered during dialectological expeditions to German villages of the Altai Krai in 2003-2013 using the methods of comparison and context analysis.

Conjunctions in the Altai German dialects, as well as in the literary German language, possess no nominative function, but are used to create and specify coordinate and subordinate syntactic relations between words and sentences. They possess a variety of forms in the upper- and low-insular Altai German dialects because of their phonetic peculiarities, presence of relict forms and close contacts with the Russian language.

The semantics of the subordinate conjunctions in the dialects under study is not as diverse as in the literary German language, but they have a certain number of meanings they express. Some of them are highly specialized, monosemantic: "weil", "hotj", "solange", while the others are polysemantic: "wi", "wo", "tass / daut / dot". The polysemantic conjunctions can introduce different subordinate clauses, their actual meaning is realized in context.

The author of the article describes the main semantic groups of subordinate conjunctions in the insular Altai German dialects, reveals the most common subordinating conjunction in every group and analyzes their main features. In the article the subordinate conjunctions are grouped in 9 classes according the relationships they express: temporal and conditional conjunction, conjunction of reason and purpose, consecutive, concessive, comparison, attributive and object conjunctions.

The analysis of practical material reveals similarities and differences between subordinate conjunctions in the contemporary literary German language and the dialects on the territory of Germany and hypotaxis constructions in oral German speech.

The author comes to a conclusion that the system of coordinate conjunctions in the dialects under study is not a closed word-class: influenced by the Russian language, the dialects borrow new elements, which opens a wide scope for further research.

\section{References}

1. Moskalyuk L.I. Sotsiolingvisticheskie aspekty rechevogo povedeniya rossiyskikh nemtsev $v$ usloviyakh bilingvizma [Sociolinguistic aspects of speech behavior of Russian Germans in a bilingual situation]. Barnaul: Barnaul State Pedagogical University Publ., 2000. 166 p.

2. Hilkes P. Zur Lage der deutschen Minderheiten in der Sowjetgesellschaft. München: Osteuropa-Institut, $1990.15 \mathrm{p}$.

3. Edig G.G. Pridatochnye predlozheniya nizhnenemetskogo govora Altayskogo kraya. Avtoref. diss. kand. filol. nauk [Clauses in the Low German dialect of Altai. Abstract of Philology Cand. Diss.]. Tomsk, 1962. $39 \mathrm{p}$.

4. Trubavina N.V. Osobennosti razvitiya zavisimykh predikativnykh konstruktsiy v ostrovnom verkhnenemetskom govore: Avtoref. diss. kand. filol. nauk [Features of the development of dependent predicative constructions in the High German insular dialect. Abstract of Philology Cand. Diss.]. Barnaul, 2003. 20 p.

5. Pirogov N.A. Sintaksis sovremennoy nizhnenemetskoy dialektnoy literatury: Avtoref. diss. kand. filol. nauk [The syntax of the modern Low German dialect literature. Abstract of Philology Cand. Diss.]. Moscow, 1980. 27 p.

6. Yartseva V.N. (ed.) Yazykoznanie: bol'shoy entsiklopedicheskiy slovar' [Linguistics: a big encyclopaedic dictionary]. 2nd edition. Moscow: Bol'shaya Rossiyskaya entsiklopediya Publ., 1998. $685 \mathrm{p}$.

7. Tesnière L. Osnovy strukturnogo sintaksisa [Foundations of structural syntax]. Translated from French by I.M. Boguslavskiy. Moscow: Progress Publ., 1988. 654 p. 
8. Peshkovskiy A.M. Russkiy sintaksis v nauchnom osveshchenii [Russian syntax in a scientific light]. 8th edition. Moscow: Yazyki slavyanskoy kul’tury Publ., 2001. 544 p.

9. Vinogradov V.V. Russkiy yazyk (Grammaticheskoe uchenie o slove) [The Russian language (Grammatical Doctrine of the Word)]. 4th edition. Moscow: Russkiy yazyk Publ., 2001. 720 p.

10. Reformatskiy A.A. Vvedenie $v$ yazykovedenie [Introduction to linguistics]. 5th edition. Moscow: Aspekt Press Publ, 2000. 536 p.

11. Gulyga E.V., Natanzon M.D. Teoriya sovremennogo nemetskogo yazyka (grammatika) [The theory of the modern German language (grammar)]. Moscow: Znanie Publ., 1959. Pt. 2, 173 p.

12. Moskal'skaya O.I. Grammatika nemetskogo yazyka: teoreticheskiy kurs [German Grammar: Theoretical course]. Moscow: Izdatel'stvo literatury na inostrannykh yazykakh Publ., 1958. 394 p.

13. Duden. Grammatik der deutschen Gegenwartssprache. Mannheim; Wien; Zürich: Bibliographisches Institut, 1984. $800 \mathrm{p}$.

14. Helbig G, Buscha J. Deutsche Grammatik. Leipzig: VEB Verlag Enzyklopädie, 1977. 629 p.

15. Schendels E.I. Deutsche Grammatik. Moskau: Verlag Hochschule, 1982. 400 p.

16. Moskalyuk L.I., Trubavina N.V. Lingvisticheskiy atlas nemetskikh dialektov na Altae: v 2 ch. [Linguistic Atlas of German dialects in the Altai: in 2 pts.]. Barnaul: AltGPA Publ., 2011. Pt. 2, 199 p.

17. Wild K. Syntax eingeleiteten Nebensätze in den "Fuldaer" Deutschen Mundarten Ungarns. Budapest: Akad.K., 1994. 257 p.

18. Weise O. Altenburger Mundart. Leipzig: Breitkopf\&Händel, 1900. 164 p.

19. Post R. Pfälzisch. Einführung in eine Sprachlandschaft. Landau/ Pfalz: Pfälzische Verlagsanstalt GmbH, 1992. 399 p.

20. Polikarpov A.M. Slozhnoe predlozhenie v sintaksise nemetskoy razgovornoy rechi [Complex sentence in the syntax of the German colloquial speech]. Arkhangelsk: Pomorsk State University named after M.V. Lomonosov Publ., 2000. 446 p.

21. Moskalskaja O.I. Deutsche Sprachgeschichte. Moskau: Verlag Hochschule, 1985. 280 p.

22. Zhirmunskiy V.M. Nemetskaya dialektologiya [German Dialectology]. Moscow, Leningrad: USSR AS Publ., 1956. 636 p. 